\title{
Cyclic guanosine monophosphate does not inhibit gonadotropin-induced activation of mitogen-activated protein kinase 3/1 in pig cumulus-oocyte complexes
}

Milan Blaha, Lucie Nemcova and Radek Prochazka*

\begin{abstract}
Background: Recent results indicate a key role for cyclic guanosine monophosphate (cGMP) in the regulation of oocyte meiotic arrest in preovulatory mammalian follicles. The aim of our study was to determine whether the resumption of oocyte meiosis and expansion of cumulus cells in isolated pig cumulus-oocyte complexes (COCs) can be blocked by a high intracellular concentration of cGMP, and whether this effect is mediated by a cGMP-dependent inhibition of mitogen-activated protein kinase 3/1 (MAPK3/1).

Methods: The COCs were isolated from ovaries of slaughtered gilts and cultured in vitro in M199 supplemented with 5\% fetal calf serum. The expression levels of the C-type natriuretic peptide (CNP) precursor (NPPC) and its receptor (NPR2) mRNAs during the culture of COCs were determined by real-time RT-PCR. To control the intracellular concentration of cGMP in the COCs, the culture medium was further supplemented with CNP or various concentrations of synthetic cGMP analogues; the concentration of CGMP in COCs was then assessed by ELISA. The effect of the drugs on oocyte maturation was assessed after 24 and $44 \mathrm{~h}$ of culture by determining nuclear maturation. The expansion of cumulus cells was assessed by light microscopy and the expression of cumulus expansion-related genes by real-time RT-PCR. A possible effect of CGMP on FSH-induced activation of MAPK3/1 was assessed by immunoblotting the COC proteins with phospho-specific and total anti-Erk1/2 antibodies.
\end{abstract}

Results: The COCs expressed NPPC and NPR2, the key components of CGMP synthesis, and produced a large amount of cGMP upon stimulation with exogenous $C N P$, which lead to a significant $(P<0.05)$ delay in oocyte meiotic resumption. The COCs also responded to CGMP analogues by inhibiting the resumption of oocyte meiosis. The inhibitory effect of CGMP on meiotic resumption was reversed by stimulating the COCs with FSH. However, high concentration of intracellular cGMP was not able to suppress FSH-induced activation of MAPK3/1 in cumulus cells, cumulus expansion and expression of expansion-related genes ( $P>0.05)$.

Conclusions: The findings of this study indicate that high cGMP concentrations inhibit the maturation of pig oocytes in vitro but the inhibitory mechanism does not involve the suppression of MAPK3/1 activation in cumulus cells.

Keywords: Pig, Oocyte, cGMP, Meiotic resumption, Expansion-related genes, MAPK3/1

\footnotetext{
* Correspondence: prochazka@iapg.cas.cz

Laboratory of Developmental Biology, Institute of Animal Physiology and

Genetics, Academy of Sciences of the Czech Republic, Rumburska 89, 27721

Libechov, Czech Republic
} 


\section{Background}

Mammalian oocytes are held in the meiotic prophase arrest induced by high intracellular concentration of cyclic adenosine monophosphate (cAMP), which is maintained by the activity of an orphan receptor GPR3 [1,2] and the inhibition of oocyte-specific phospodiesterase 3A (PDE3A) $[3,4]$. Mouse PDE3A was found to be inhibited by cyclic guanosine monophosphate (cGMP) diffusing from granulosa cells $[5,6]$. Cyclic GMP is synthetized by natriuretic peptide receptor 2 (NPR2) [7], a key membrane-bound guanylyl cyclase expressed in follicular cells [8]. The concentration of cGMP in the preovulatory follicle decreases in response to luteinizing hormone (LH) [6].

In mice, $\mathrm{LH}$ activates two principal pathways that lead to a reduction in cGMP concentration in the oocyte. The first pathway consists of a reduction in cGMP transport from somatic follicular cells to the oocyte. This pathway is dependent on the kinase activity of the epidermal growth factor receptor (EGFR) and mitogen-activated protein kinases 3/1 (MAPK3/1) that are required for the phosphorylation of connexin 43 and gap junction closure [9-11]. In response to LH stimulus, EGF-like factors amphiregulin (AREG) and epiregulin (EREG) are expressed and released from mural granulosa cells in mice [12]. These peptides then trigger the resumption of meiosis and cumulus expansion in mice [12], pigs [13] and humans [14]. Both AREG and EREG are also able to cause a decrease in cGMP in cultured follicles [6]. However, the cGMP level may be reduced in somatic cells of the follicle even if the EGFR activity is inhibited or absent [10].

The second pathway of cGMP decrease in the mouse preovulatory follicle is based on the regulation of cGMP synthesis and hydrolysis. LH downregulates the expression of C-type natriuretic peptide precursor $(N P P C)$ in granulosa cells and causes a rapid decline in C-type natriuretic peptide (CNP), a ligand and activator of the NPR2 [15]. In addition, LH rapidly decreases activity of the NPR2 without reducing the amount of NPR2 protein [8]. Next, the LH surge inhibits the production of estradiol that is essential for the promotion and maintenance of NPR2 expression [16]. Finally, the cGMP level in follicular cells may be efficiently reduced by an increased activity of the cGMP-hydrolyzing enzymes. In support of this assumption, the cGMP-specific phosphodiesterase activity (types 5/6) as well as the amount of PDE6C protein are increased in porcine oocyte-cumulus complexes (COCs) cultured in the presence of human chorionic gonadotropin and equine chorionic gonadotropin [17].

The hyaluronan synthase 2 (HAS2), prostaglandinendoperoxide synthase 2 (PTGS2) and tumor necrosis factor alpha-induced protein 6 (TNFAIP6) have been shown to play key roles in the regulation of cumulus expansion [18-20]. The expression levels of these genes are increased by EGF-like peptides in the response to
LH signaling in vivo and also after the addition of exogenous EGF-like peptides to cultured COCs in mice [21] and pigs [13]. MAPK3/1 activation in cumulus cells is absolutely essential for the expression of the cumulus expansionrelated genes [21-24]. The most compelling evidence of the pivotal role of MAPK3/1 in the control of ovulation processes came from experiments with granulosa-cell-specific $M A P K 3 / 1$ double-knockout mice that failed to ovulate and the females were completely infertile [22]. In concert with these observations, the expression of HAS2, TNFAIP6 or PTGS2 was completely abolished in these MAPK $3 / 1$ null mice.

Several lines of evidence indicate that cGMP may block meiotic resumption and cumulus expansion via a MAPK3/1-dependent mechanism, since the activation of MAPK3/1 in cumulus cells is essential for these processes to occur [25]. An activator of a soluble guanylyl cyclase and nitric oxide (NO) donor, S-nitroso-N-acetylpenicillamine (SNAP), was found to prevent $\mathrm{LH}$-induced MAPK3/1 activation in cultured rat follicles and to inhibit oocyte meiotic resumption and cumulus expansion [26]. Correspondingly, a guanylyl cyclase inhibitor $1 \mathrm{H}-[1,2,4]$ oxadiazolo[4,3-a]quinoxalin-1-one mimicked the action of $\mathrm{LH}$ and induced MAPK3/1 phosphorylation [26]. However, no direct effect of cGMP on MAPK3/1 or an upstream signal transduction pathway was shown in that study. In porcine COCs, both atrial natriuretic peptide (ANP) and 8-bromo-cGMP (8-Br-cGMP) in doses of 0.5 and $1.0 \mathrm{mM}$ moderately inhibited FSH-induced oocyte maturation and cumulus expansion and partially reduced the phosphorylation of MAPK3/1 in both oocytes and cumulus cells [27]. The analysis of MAPK $3 / 1$ activity was carried out at the end of the culture period in that study and the significance of this finding in terms of the regulation of early events of meiotic resumption is not clear. In a recent paper, Santiquet et al. [28] reported no effect of ANP itself on cGMP production and FSH-induced meiotic resumption of pig cumulus-enclosed oocytes and the cGMP analogues only exhibited an inhibitory effect at a concentration of $5 \mathrm{mM}$, well above the range used in all previously published studies. The effect of CNP on the maturation of intact pig COCs is not clear either. So far, it has been shown that CNP inhibits the meiotic resumption of pig cumulus-enclosed oocytes pre-cultured for $22 \mathrm{~h}$ in dibutyryl cAMP [29]. Santiquet et al. [28] reported an inhibition of meiotic resumption in pig cumulus-enclosed oocytes treated with $10 \mu \mathrm{M}$ CNP whereas $\mathrm{nM}$ concentrations are effective in mice [15]. We assumed that further studies would be needed to clarify the role of cGMP in regulation of pig oocyte meiotic resumption and cumulus expansion.

The aim of this study was to determine whether the resumption of oocyte meiosis and expansion of cumulus cells in isolated pig COCs can be blocked by high levels 
of cGMP and whether this effect is mediated by the cGMP-dependent inhibition of MAPK3/1 in cumulus cells.

\section{Methods}

The study was conducted in the laboratories of IAPG in Libechov in 2013 and 2014. All the procedures with animals were performed according to good veterinary practice for animal welfare according to the relevant Czech laws (No. 246/1992 and 419/2012).

\section{Culture media and reagents}

All chemicals were purchased from Sigma (Prague, Czech Republic) unless otherwise specified.

\section{Collection of cumulus-oocyte complexes}

Ovaries were obtained from premature crossbred gilts (Landrace and Large White), 6-8 months old and 90$120 \mathrm{~kg}$ in weight, originating from two commercial breeding farms. The animals were slaughtered at a local abattoir in the city of Mimon, their ovaries excised and transported to the laboratory in a thermo-flask at $38^{\circ} \mathrm{C}$. The contents of medium-size antral follicles about 3-5 mm in diameter were aspirated with a syringe connected to $20 \mathrm{G}$ needle, pooled in a test-tube and allowed to sediment for $10 \mathrm{~min}$. The sediment was washed twice with PBS, placed in a Petri dish and the COCs were collected by a pipette. Only COCs surrounded by compact multi-layered cumulus were selected for experiments.

\section{Culture of cumulus-oocyte complexes in vitro}

The COCs were cultured in M-199 medium (Gibco, Life Technologies, Rockville, USA) supplemented with $0.91 \mathrm{mM}$ sodium pyruvate, $0.57 \mathrm{mM}$ cysteine, $5.5 \mathrm{mM}$ Hepes, antibiotics and fetal calf serum (5\%). Groups of 25-30 COCs were cultured in four-well dishes (Nunclon, Roskilde, Denmark) in $0.5 \mathrm{ml}$ of culture medium at $38.5^{\circ} \mathrm{C}$ in a humidified atmosphere of $5 \% \mathrm{CO}_{2}$. To stimulate the expansion of cumulus cells and oocyte maturation, the culture medium was supplemented with follicle-stimulating hormone (FSH) from sheep pituitary. Denuded oocytes were prepared mechanically by a repeated pipetting of intact COCs through a fine bore pipette.

\section{Assessment of oocyte maturation and cumulus expansion} To assess their nuclear maturation, oocytes were stripped of cumulus cells by vortexing, mounted on slides and fixed in an acetic acid-ethanol solution (1:3) for $48 \mathrm{~h}$. Oocytes were then stained with $1 \%$ orcein and observed with a light microscope. Oocytes were scored for germinal vesicle (GV), germinal vesicle breakdown (GVBD; comprising mostly oocytes at metaphase I stage and few oocytes at late diakinesis, anaphase I or telophase I) and for metaphase II stage (MII). The degree of cumulus expansion was assessed $24 \mathrm{~h}$ after the onset of culture using a subjective scoring method [30]. Briefly, no response was scored as 0 , minimum observable response, the cells in outermost layer of the cumulus becoming round and glistening as 1 , the expansion of outer COCs layers as 2, the expansion of all COCs layers apart from corona radiata as 3 and the expansion of all COCs layers as 4. COCs exhibiting degree 3 and 4 were considered to be expanding.

\section{Measurement of cGMP concentration in COCs}

Groups of 30 control, cGMP analogue-, or CNP-treated COCs were cultured for various time intervals, carefully washed in three large drops of PBS, and then lysed in $200 \mu \mathrm{l}$ of $0.1 \mathrm{M} \mathrm{HCl}$ supplemented with Triton X-100 $(0.01 \%)$ at room temperature for $30 \mathrm{~min}$. During this period, the samples were briefly and vigorously vortexed every $10 \mathrm{~min}$ and centrifuged at the end of the lysis period at $10000 \mathrm{~g}$ for $1 \mathrm{~min}$. The supernatant was transferred into a new tube and stored at $-20^{\circ} \mathrm{C}$ until use. The cGMP concentrations in the samples were determined with a cGMP complete ELISA kit (Enzo Life Sciences, Famingdale, NY, USA) according to the manufacturer's instructions. Briefly, $100 \mu \mathrm{l}$ of cGMP standards or samples were added to wells coated with affinity-purified antibody (goat-anti rabbit IgG). A blue solution of cGMP conjugated to alkaline phosphatase (ALP) was then added, followed by a yellow solution of rabbit polyclonal antibody to cGMP. The plate was incubated for $2 \mathrm{~h}$ on a shaker at room temperature to promote the immune reaction of endogenous and ALP-conjugated exogenous cGMP with the antibody and binding of the complex to the affinity antibody. The wells were emptied after incubation and extensively washed three times with the supplied wash-buffer to leave only bound cGMP in the wells. A total of $200 \mu \mathrm{l}$ of p-nitrophenyl phosphate solution, an alkaline phosphatase substrate, was then added into each well and the plate was incubated for $1 \mathrm{~h}$ at room temperature in the dark without shaking. The reaction was stopped by trisodium phosphate solution and the amount of signal, proportional to the amount of cGMP in the sample, was measured with an ELISA plate reader (Synergy HT, BioTek, Winooski, VT, USA) at $405 \mathrm{~nm}$. The cGMP concentrations in the samples were calculated from a standard curve and are expressed as fmol cGMP/COC.

Real-time reverse transcription-polymerase chain reaction The total RNA from 30 COCs cultured for various periods of time was isolated using RNeasy Mini Kit (Qiagen, Hilden, Germany) following the manufacturer's instructions. Real-time RT-PCR was carried out in a RotorGene 3000 cycler (Corbett Research, Sydney, Australia) using One-Step RT-PCR Kit (Qiagen) with gene specific primers shown in Table 1 . The $20 \mu \mathrm{l}$ total reaction volume contained QIAGEN OneStep RT-PCR Buffer (1×), dNTP Mix (400 $\mu \mathrm{M}$ final concentration of each), reverse and 
Table 1 Primers used for real-time RT-PCR

\begin{tabular}{|c|c|c|c|c|}
\hline Gene transcript & Primers & Amplicon length (bp) & $\mathrm{T}_{\mathrm{an}}\left({ }^{\circ} \mathrm{C}\right)$ & GenBank accession number \\
\hline \multirow[t]{2}{*}{$\overline{A C T B}$} & F: 5' - GAG AAG CTC TGC TAC GTC G - 3' & 264 & 58 & XM_3357928 \\
\hline & R: 5' - CCA GAC AGC ACC GTG TTG G - 3' & & & \\
\hline \multirow[t]{2}{*}{ HAS2 } & F: 5' - GAA GTC ATG GGC AGG GAC AAT TC - 3' & 407 & 54 & NM_214053 \\
\hline & R: 5' - TGG CAG GCC CTT TCT ATG TTA - 3' & & & \\
\hline \multirow[t]{2}{*}{ NPPC } & F: 5'- AGA AGG GCG ACA AGA CTC CT - 3' & 182 & 59 & NM_001008482 \\
\hline & R: 5'- GAA GCA GCC CTT GGA CAA AC - 3 & & & \\
\hline \multirow[t]{2}{*}{ NPR2 } & F: 5'- TGC TTा GAT GCC ATA ATT GA - 3' & 137 & 50 & NM_001244322 \\
\hline & R: 5'-AAT GCT AGG GCC ATA CGA G - 3' & & & \\
\hline \multirow[t]{2}{*}{ PTGS2 } & F: 5' - TCG ACC AGA GCA GAG AGA TGA GAT - 3' & 260 & 55 & NM_214321 \\
\hline & R: 5' - ACC ATA GAG CGC TTC TAA CTC TGC - 3' & & & \\
\hline \multirow[t]{2}{*}{ TNFAIP6 } & F: $5^{\prime}$ - CAG AAG ACA TCA TTA GTA - 3' & 150 & 54 & NM_001159607 \\
\hline & R: 5' - CAG TAG AAG TAG TAG TTG - 3' & & & \\
\hline
\end{tabular}

$\mathrm{T}_{\mathrm{an}}$ - annealing temperature.

forward primers (both $400 \mathrm{nM}$ final concentration), SybrGreenI $(0.4 \mu \mathrm{l}$ of 1:1000 stock solution, Molecular Probes, Eugene, OR, USA), RNasine inhibitor (5 IU, Promega, Madison, WI, USA), QIAGEN OneStep RT-PCR Enzyme Mix $(0.8 \mu \mathrm{l})$ and template RNA $(2 \mu \mathrm{l})$. The reaction conditions were as follows: reverse transcription at $50^{\circ} \mathrm{C}$ for $30 \mathrm{~min}$, pre-denaturation at $95^{\circ} \mathrm{C}$ for $15 \mathrm{~min}$, followed by various numbers of PCR cycles, each of which consisted of denaturation at $95^{\circ} \mathrm{C}$ for $30 \mathrm{sec}$, annealing at a temperature specific for each pair of primers (shown in Table 1) for $20 \mathrm{sec}$, extension at $72^{\circ} \mathrm{C}$ for $20 \mathrm{sec}$, and a final extension step at $72^{\circ} \mathrm{C}$ for $5 \mathrm{~min}$. The specificity of the PCR product was verified by melting analysis. The relative concentrations of the templates in the various samples were determined using comparative analysis software (Corbett Research). The results for individual target genes were normalized according to the relative concentration of the internal standard, ACTB.

\section{Immunoblotting}

At the selected culture time, COCs were washed in PBS and solubilized in Laemmli buffer containing $2 \%$ sodium dodecyl sulphate (SDS) and 5\% 2-mercaptoethanol. Samples were boiled at $100^{\circ} \mathrm{C}$ for $3 \mathrm{~min}$ and stored frozen at $-20^{\circ} \mathrm{C}$. Subsequently, proteins were separated in 10\% acrylamide/SDS gels and transferred to Immobilon-P membranes (Millipore, Bedford, MA, USA). Membranes were blocked in $5 \%$ low-fat dry milk in Tris-buffered saline (TBS) with $0.5 \%$ Tween 20 for $2 \mathrm{~h}$ at room temperature and then incubated with a primary antibody diluted 1:1000 in $5 \%$ BSA in TBS-Tween, at $4^{\circ} \mathrm{C}$ overnight. The primary antibodies were p-ERK and ERK1 (detecting MAPK3/1), both from Santa Cruz Biotechnology (Santa Cruz, CA, USA). The secondary antibodies (Amersham ECL antimouse or anti-rabbit IgG, GE Healthcare, Little Chalfont, UK) were diluted 1:5000 in 2\% BSA in TBS-Tween. The membranes were incubated with the secondary antibody for $1 \mathrm{~h}$ at room temperature and washed intensively in TBS-Tween. The immune reaction was detected by enhanced chemiluminescence (Pierce, Rockford, IL, USA) according to the manufacturer's instructions. The intensity of the specific bands on the blots was analyzed by scanning densitometry using the free software Image J Version 1.29 (National Institute of Mental Health, Bethesda MD, USA).

\section{Experimental design}

Experiment I examined the expression of NPR2 and $N P P C$ during the culture of COCs in vitro $(0-20 \mathrm{~h})$.

Experiment II assessed the effect of cGMP analogues on intracellular cGMP concentration in the COCs. For this purpose, we used two synthetic cGMP analogues, 8-chlorophenylthio-cGMP (8-CPT-cGMP) and 8-Br-cGMP (both $0.1-1.0 \mathrm{mM}$ ) to control the concentrations of cGMP in the pig COCs. In all cases, the cGMP concentration in COCs was measured with a cGMP complete ELISA kit that recognized the endogenously produced cGMP and, as we found in preliminary experiments, also the synthetic cGMP analogues.

In Experiment III, the dynamics of cGMP production upon the stimulation of the COCs with CNP was monitored during the culture in vitro $(0-20 \mathrm{~h})$ and the effect of FSH on the CNP-stimulated production of cGMP was evaluated. For this purpose, the COCs were pre-cultured in CNP-supplemented medium for $1 \mathrm{~h}$ and then FSH was added to the cultured COCs. Alternatively, CNP and FSH were added simultaneously at the beginning of culture.

In Experiment IV, we assessed the effect of 8-CPTcGMP, 8-Br-cGMP and CNP on the maturation of oocytes, the expansion of cumulus cells and expression of cumulus expansion- related genes. The COCs were exposed to the 
cGMP analogues or CNP for $1 \mathrm{~h}$ before the addition of $\mathrm{FSH}$. The time of FSH addition was then taken to be time $0 \mathrm{~h}$.

Finally, in Experiment $V$, we investigated the effect of 8-CPT-cGMP and CNP on the FSH-induced activation of MAPK $3 / 1$ in cumulus cells.

\section{Statistical analysis}

The statistical analyses were performed with the software GraphPad Prism 5.0 (La Jolla, CA, USA). Each experiment was performed in at least 3 replicates. The differences in the percentages of maturing oocytes, the concentration of cGMP in COCs, the densitometrical quantifications of MAPK3/1 and the quantifications of RT-PCR results were compared by the analysis of variance (ANOVA) followed by Tukey's post-test as in previous papers published by our and other laboratories $[2,6,8,13,21,23,24,28]$. The temporal differences in maturation and the differences in CGMP concentration between control and CNP treated COCs or FSH and $\mathrm{FSH}+\mathrm{CNP}$ treated COCs were compared by unpaired $t$ test. The Kolmorogov-Smirnov test was used to examine normal distribution of all data. A level of $\mathrm{P}<0.05$ was considered significant. Error bars indicate the standard error of the mean (SEM).

\section{Results}

\section{Expression of NPPC and NPR2 in cultured COCs}

This experiment confirmed the expression of both genes involved in the production of cGMP in freshly isolated pig COCs. However, the pattern of NPR2 expression during the culture in vitro with $\mathrm{FSH}$ was markedly different from that of NPPC. We found that the expression of NPR2 in the FSH-stimulated COCs significantly $(\mathrm{P}<0.05)$ decreased after $4 \mathrm{~h}$ of culture and remained low until the end of the experiment at $20 \mathrm{~h}$. In contrast, the expression of the NPR2 ligand, NPPC remained stable $(\mathrm{P}>0.05)$ over the whole of the culture period (Figure 1).
Effect of CNP and FSH on the concentrations of cGMP in cultured COCs

Consistent with our finding that both the NPR2 and NPPC genes are expressed in intact COCs, CNP (100 nM) was found to be highly capable of stimulating the production of cGMP in the cultured COCs. The concentration of cGMP in COCs increased approximately 15-fold during the first $h$ of culture $(\mathrm{P}<0.01)$ and peaked at $4 \mathrm{~h}$ of culture, exhibiting an approximately 30-fold increase over the base level $(\mathrm{P}<0.001)$ (Figure $2 \mathrm{a})$. The $\mathrm{CNP}$-stimulated concentrations of cGMP remained high (>600 fmol/COC) during the first $8 \mathrm{~h}$ of culture, dropped to approximately $300 \mathrm{fmol} / \mathrm{COC}$ at $12 \mathrm{~h}$ and returned to a base level at $16 \mathrm{~h}$. FSH suppressed the dramatic CNP-induced increase in cGMP concentration if added simultaneously with CNP (Figure 2a). However, the high level of cGMP induced by $1 \mathrm{~h}$ pre-culture of the COCs with CNP was not reduced by FSH for $8 \mathrm{~h}$ of culture, but it was significantly $(\mathrm{P}<0.01)$ lowered at $12 \mathrm{~h}$ of culture (Figure $2 \mathrm{~b})$.

cGMP analogues increase cGMP concentration in cultured COCs

Both 8-Br-cGMP and 8-CPT-cGMP (0.1-1.0 mM) significantly $(\mathrm{P}<0.05)$ increased the concentration of a measurable intracellular cGMP in the COCs at $4 \mathrm{~h}$ of culture to levels comparable with those seen in the CNP-treated COCs (Figure 3).

cGMP analogues and CNP affect maturation of porcine oocytes, but not expansion of cumulus cells

In vitro, exogenous 8-Br-cGMP and 8-CPT-cGMP (0.5$1.0 \mathrm{mM}$ ) efficiently blocked the maturation of denuded oocytes (Figure 4, a and b) as well as the spontaneous maturation of COCs (1 mM) (Figure 4, c and d), since significantly more oocytes remained at the GV stage compared to the control group of denuded oocytes or COCs cultured in the medium without analogues. The inhibitory effect of the cGMP analogues on COCs maturation was completely reversed by the addition of FSH
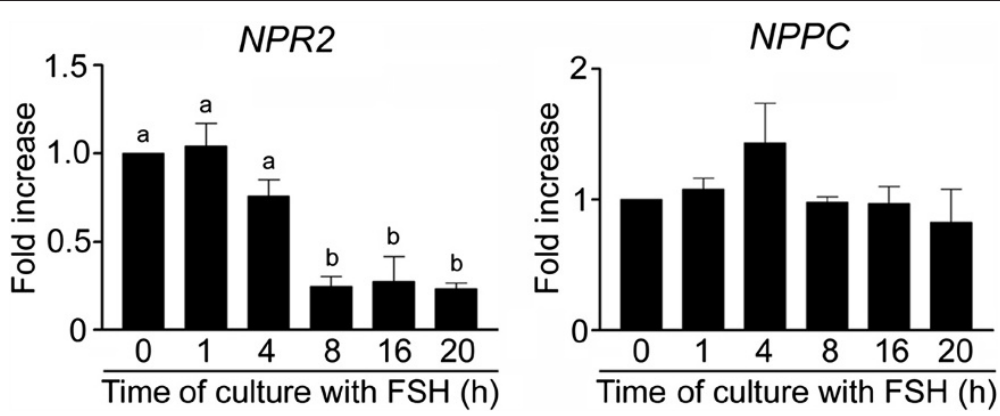

Figure 1 Expression of NPR2 and NPPC in COCs cultured in vitro in FSH-supplemented medium. The relative abundance of specific gene mRNA was assessed in COCs cultured with FSH $(1 \mathrm{IU} / \mathrm{ml})$ for the indicated periods of time by a real-time RT-PCR and is expressed in arbitrary units as fold increases in the specific gene/ACTB ratio over the level found in control COCs at time $0 \mathrm{~h}$. The different superscripts above the columns indicate significant differences $(P<0.05)$ 


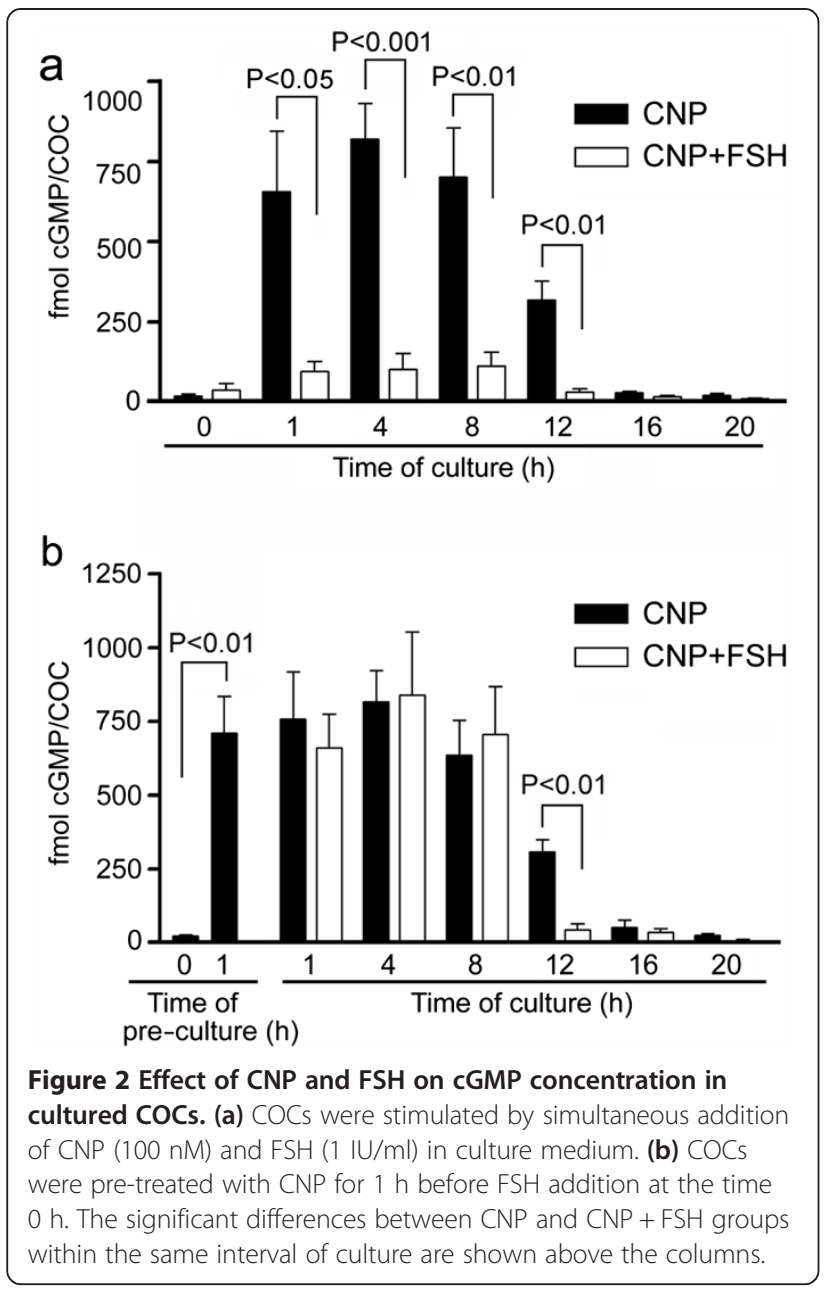

into the culture medium in a dose as low as $0.1 \mathrm{IU} / \mathrm{ml}$ (Figure 4, $\mathrm{c}$ and d).

The effect of CNP was only tested on COCs, since NPR2 receptors are present on the surface of cumulus cells, but not on the oocyte itself $[7,31]$. The CNP neither affected the spontaneous maturation of the COCs (Figure 5a) nor the FSH-induced maturation of COCs assessed after $44 \mathrm{~h}$ of culture (Figure $5 \mathrm{~b}$ ). However, we
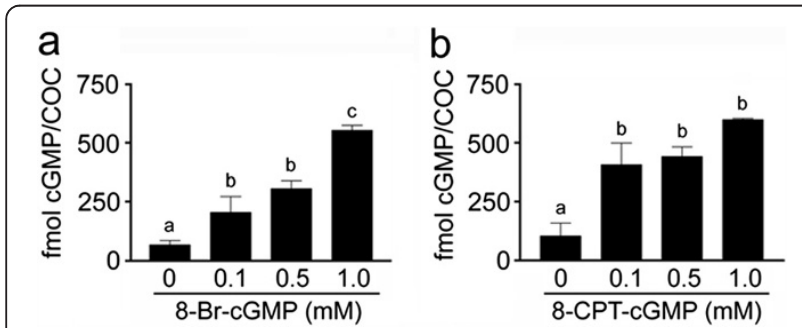

Figure 3 Effect of cGMP analogues on cGMP concentration in cultured COCs. (a) COCs were cultured in medium supplemented with various concentrations of 8-Br-cGMP or (b) 8-CPT-cGMP for $4 \mathrm{~h}$. The different superscripts above the columns indicate significant differences $(P<0.05)$. found that CNP significantly $(\mathrm{P}<0.05)$ decreased the percentage of COCs that underwent GVBD after $24 \mathrm{~h}$ of culture (Figure 5b). This indicates that the CNP-induced increase in cGMP concentration delayed the FSH-induced meiotic resumption of pig oocytes in vitro.

The COCs did not undergo expansion in the control medium (Figure 6a). In contrast, all COCs underwent expansion in the FSH-supplemented medium (Figure 6b). Both cGMP analogues as well as the CNP neither stimulated expansion of the COCs (Figure 6, c, e and g) nor decreased the degree of FSH-stimulated cumulus cell expansion since virtually all COCs ( $n=75$ in each group) exhibited an expansion of all layers of cumulus cells except the corona radiata cells (Figure 6, d, f and h).

\section{CNP and CGMP analogues did not downregulate the expression of cumulus expansion-related genes}

The expression of HAS2, PTGS2 and TNFAIP6 in COCs was enhanced approximately 17, 20 and 1000-fold by $\mathrm{FSH}$, respectively, at $4 \mathrm{~h}$ of culture. The FSH-induced expression of each specific gene was not significantly $(\mathrm{P}>0.05)$ affected by CNP (Figure 6i) or by the cGMP analogues (Figure 6j).

\section{MAPK3/1 activation was not affected by high concentration of cGMP}

By immunoblotting with phospho-specific antibodies, we detected a significant $(\mathrm{P}<0.05)$ increase in MAPK3/1 phosphorylation in FSH-stimulated COCs at $4 \mathrm{~h}$ of culture. Neither CNP nor 8-CPT-cGMP affected the basal level of MAPK3/1 phosphorylation and did not reduce MAPK3/1 phosphorylation induced by FSH $(\mathrm{P}>0.05)$ (Figure 7a). The high level of MAPK 3/1phosphorylation persisted in FSH-stimulated COCs for at least $32 \mathrm{~h}$ of culture, when the cumuli displayed maximum expansion. The cGMP analogue (8-CPT-cGMP, $1 \mathrm{mM}$ ) did not change the pattern of MAPK 3/1 phosphorylation during the culture of COCs in vitro (Figure 7b).

\section{Discussion}

The data from our study show, for the first time in a non-rodent species, the pattern of NPPC and NPR2 expression in COCs cultured in vitro. Both $N P P C$ and NPR2 are expressed in the intact COCs, but only the NPR2 seems to be downregulated during the culture in vitro with FSH. The NPR2 downregulation observed in our study may thus be involved in the decrease in cGMP contents in cumulus cells and consequently in the oocyte. Therefore, this step may participate in the regulation of meiotic resumption in cultured pig oocytes. The downregulation of NPR2 in the COCs occurred between 4 and $8 \mathrm{~h}$ of culture, which further supports the possible role of this gene in the regulation of meiotic resumption since all essential morphological events 

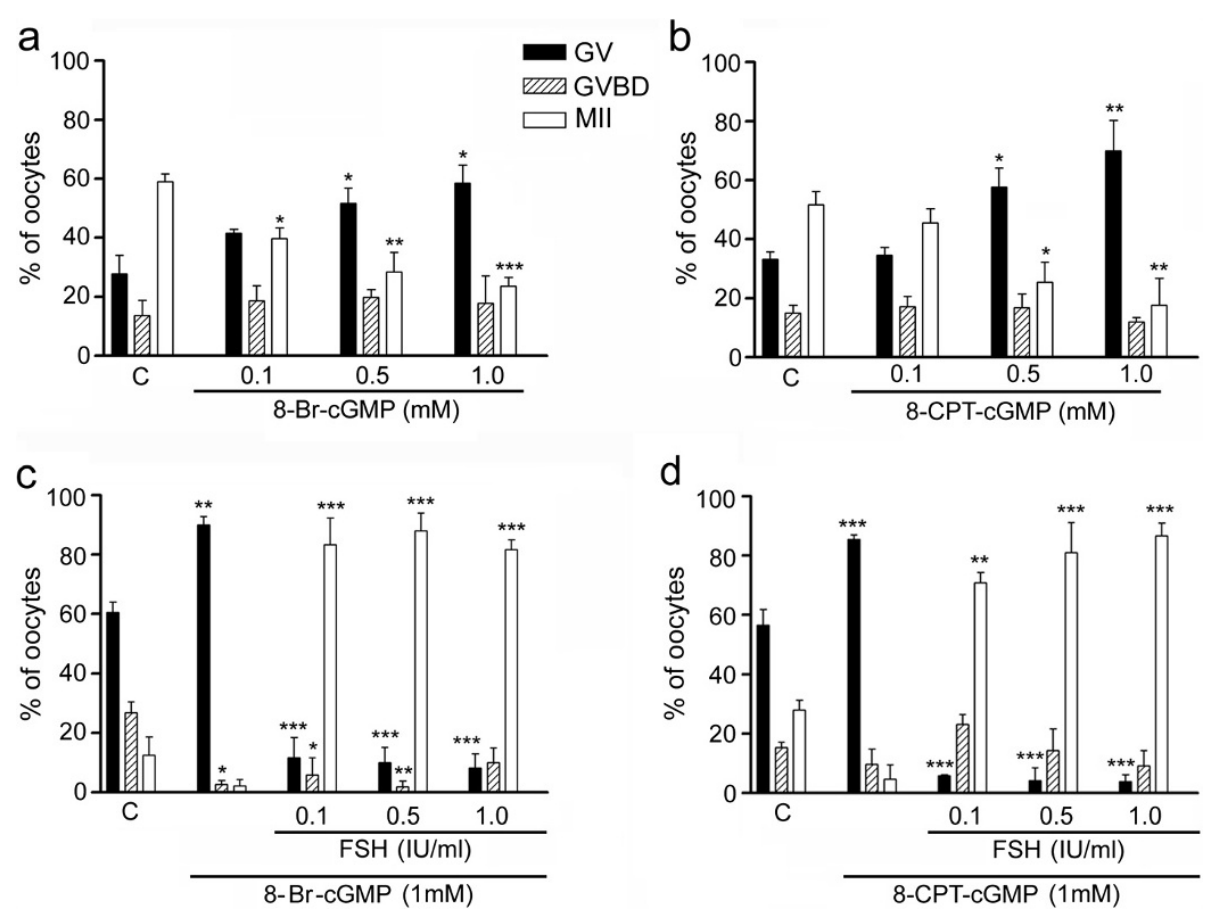

Figure 4 Effect of cGMP analogues on maturation of pig denuded oocytes and COCs. (a) Maturation of denuded oocytes cultured in medium supplemented with various concentrations of 8-Br-cGMP or (b) 8-CPT-cGMP for $44 \mathrm{~h}$. (c) Effect of FSH on maturation of COCs in medium supplemented with $1 \mathrm{mM}$ 8-Br-cGMP or (d) $1 \mathrm{mM}$ 8-CPT-cGMP for 44 h. C, control oocytes or COCs cultured in medium without FSH and cGMP analogues; GV, germinal vesicle; GVBD, germinal vesicle breakdown; MII, metaphase II. Asterisks above the column indicate significant differences from the corresponding value in the control group. ${ }^{*} \mathrm{P}<0.05$; ${ }^{* *} \mathrm{P}<0.01 ;{ }^{* * *} \mathrm{P}<0.001$. Approximately 75 denuded oocytes or COCs were included in each group.

associated with the transition of pig oocytes from GV to metaphase I, such as chromosome condensation and nuclear membrane breakdown, occur after $8 \mathrm{~h}$ of culture in vitro [32]. In principle, two mechanisms leading to a decrease in cGMP production in the granulosa and cumulus cells of preovulatory follicles have been described. The first is a LH-induced decrease in the expression of NPPC leading to a significant drop in ovarian $\mathrm{CNP}$ content $2 \mathrm{~h}$ after hCG injection [15]. The second is a LH-inhibited activity of the NPR2 that occurs in granulosa cells in a post-translational manner within 10-20 min $[8,33]$, followed by a reduced activity of NPR2 in cumulus cells that occurs within $2 \mathrm{~h}$ [8]. It follows that both mechanisms may play a role in the promotion of meiotic resumption in the mouse, since GVBD was found in that study at $3 \mathrm{~h}$ after hCG injection [8]. In pig COCs cultured in vitro, only a FSH-induced decrease in NPR2 expression appears to be involved in the regulation of meiotic resumption, as proposed in our study.

The reduction of cGMP transport from somatic follicular cells to the oocyte is another mechanism contributing to the release of oocytes from meiotic arrest. In mice and rats, gonadotropins may induce rapid gap junction closure via activation of the MAPK3/1-dependent pathway [34] and thus avoid the diffusion of cGMP into the oocyte.
However, the role of gap junction permeability in meiotic resumption in pigs is still not clear. Surprisingly, gap junction permeability is increased in a gonadotropinindependent manner during the first hours of COCs culture and a gonadotropin-dependent closure of gap junctions occurs before or simultaneously with GVBD $[35,36]$. Thus, it appears that the deregulation of gap junctions may play a role in the initiation of meiotic resumption in pig COCs. However, it does not occur immediately after gonadotropin stimulation, as proposed in rodent models, but is postponed beyond $8 \mathrm{~h}$ of culture, reflecting the extended period of time required for GVBD in pig oocytes. Taken together with our data, it appears that both downregulation of NPR2 and a reduction in gap junction communication may contribute to the decline in cGMP in cumulus cells and oocytes, respectively, and to meiotic resumption of pig oocytes in vitro.

In agreement with the expression of NPPC and NPR2 found in our study, the COCs were highly responsive to exogenous CNP in terms of cGMP production. Stimulation of the COCs with $100 \mathrm{nM}$ CNP resulted in an approximately 30 -fold increase in the basal level of cGMP in $4 \mathrm{~h}$. This is in agreement with data reported for the mouse COCs, where 10-100 nM of CNP induced several-fold 


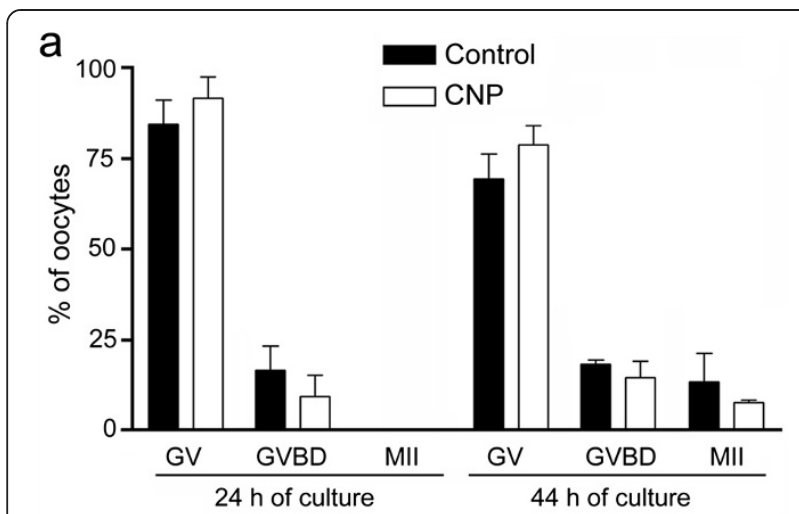

b

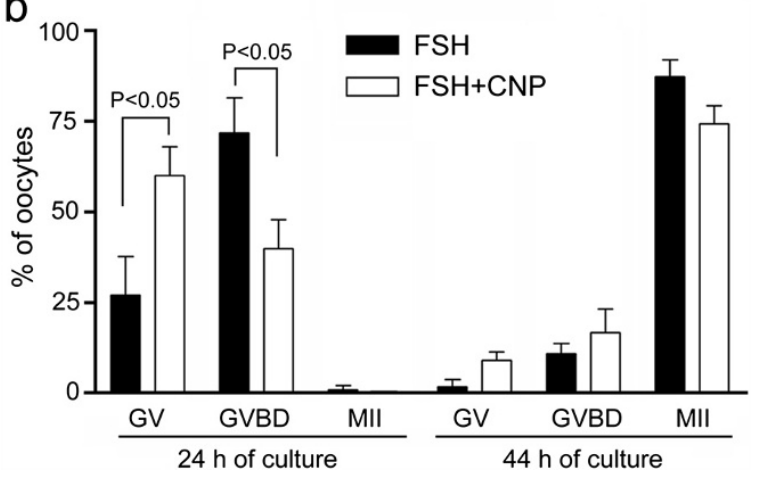

Figure 5 Effect of CNP on spontaneous and FSH-induced maturation of pig cumulus-enclosed oocytes. (a) Effect of CNP (100 nM) on spontaneous maturation of oocytes. (b) Effect of CNP on maturation of oocytes induced by FSH (1 IU/ml). GV, germinal vesicle; GVBD, germinal vesicle breakdown; MII, metaphase II. Significant differences were only found between FSH and FSH + CNP groups after $24 \mathrm{~h}$ of culture. Approximately 75 COCs were included in each group.

increases in cGMP concentration, associated with the inhibition of oocyte meiotic resumption [15,37]. However, the concentration as high as $10 \mu \mathrm{M}$ of $\mathrm{CNP}$ was required for inhibition of FSH-induced meiotic resumption in pig oocytes, which was associated with a threefold increase in cGMP concentration in the COCs after $24 \mathrm{~h}$ of culture [29]. We found that nM concentrations of CNP caused up to 30-fold increase in cGMP levels in COCs during the first $8 \mathrm{~h}$ of culture and that the cGMP levels returned to a base after 16-20 h of culture. Next, we showed that FSH prevented the rise in cGMP from the basal concentrations, if added simultaneously with CNP. A possible explanation of this phenomenon is that FSH caused a rapid desensitization of NPR2 via protein kinase C and calciumdependent signaling and reduced thus NPR2 affinity for CNP as observed in 293 T-NPRB cells [38]. Finally, we showed that FSH did not reduce the high cGMP levels generated in CNP-pre-cultured COCs during the first $8 \mathrm{~h}$ of culture, but it accelerated the drop in cGMP to a base level thereafter. In pigs, cGMP-specific phosphodiesterases
$5 \mathrm{~A}$ and $6 \mathrm{C}$ were permanently upregulated beyond $12 \mathrm{~h}$ of culture COCs in the response to gonadotropin stimulation [17]. These cGMP-specific phosphodiesterases may also be responsible for the FSH-accelerated decrease in cGMP concentration observed in our study.

In this study, we also focused on the effect of cGMP analogues on the maturation of porcine denuded and cumulus-enclosed oocytes. The analogues dramatically increased the intracellular concentration of measurable cGMP in the COCs and significantly decreased the percentage of oocytes resuming meiosis. The cGMP analogues may inhibit meiotic resumption via the same mechanism as the endogenously produced cGMP, i.e. by inhibiting the oocyte PDE3A [5,6]. However, we cannot preclude alternative mechanism(s). Zhang et al. [27,39] reported that protein kinase G-specific inhibitor KT5823 reversed the inhibitory effects of ANP and 8-Br-cGMP on porcine $\mathrm{COC}$ meiotic maturation, suggesting the possible involvement of this kinase. In this study, the inhibitory effect of cGMP analogues on maturation of cumulus enclosed oocytes was completely reversed by the addition of FSH into the medium at a concentration as low as $0.1 \mathrm{IU} / \mathrm{ml}(\sim 10 \mathrm{ng} / \mathrm{ml})$. This is in contrast to data published by Zhang et al. [27,39], who reported a moderate inhibitory effect of 8 -Br-cGMP on FSH-induced maturation of pig cumulus-enclosed oocytes. This discrepancy with our findings may be due to a different source and concentration of FSH, different culture medium (NCSC 37 vs. M199) and different protein supplement (follicular fluid vs. FCS).

The mechanism by which FSH overcomes the cGMP analogue-induced meiotic block is not completely clear. A possible explanation is that FSH caused a closure of gap junctions thereby limiting the supply of the analogue transported from cumulus cells to the oocyte. However, the direct influx of the analogues from the surrounding medium to the oocyte seems sufficient to block meiosis, as indicated by the inhibitory effect of cGMP analogues on meiotic resumption in denuded oocytes. Therefore, FSH may trigger an alternative pathway that can decrease or bypass the high intracellular concentration of cGMP and consequently also cAMP in oocytes. It has been shown that FSH can trigger meiotic resumption in mammalian oocytes inhibited at the GV stage by drugs increasing the intracellular concentration of cAMP, like hypoxanthine [40], dibutyryl cAMP [41] or PDE3A inhibitors [42] via a mechanism involving the protein kinase $C$ and EGFR/MAPK3/1 pathways $[41,43,44]$. Moreover, the cGMP analogues are probably hydrolyzed in the COCs by cGMP-specific phosphodiesterases, the activity of which may be affected by FSH. In support of these assumptions, an inhibitor of phosphodiesterase 9A (PDE9A) enhanced the negative effect of 8 -Br-cGMP on mouse oocyte meiotic resumption [45]. As mentioned previously, PDE5A 


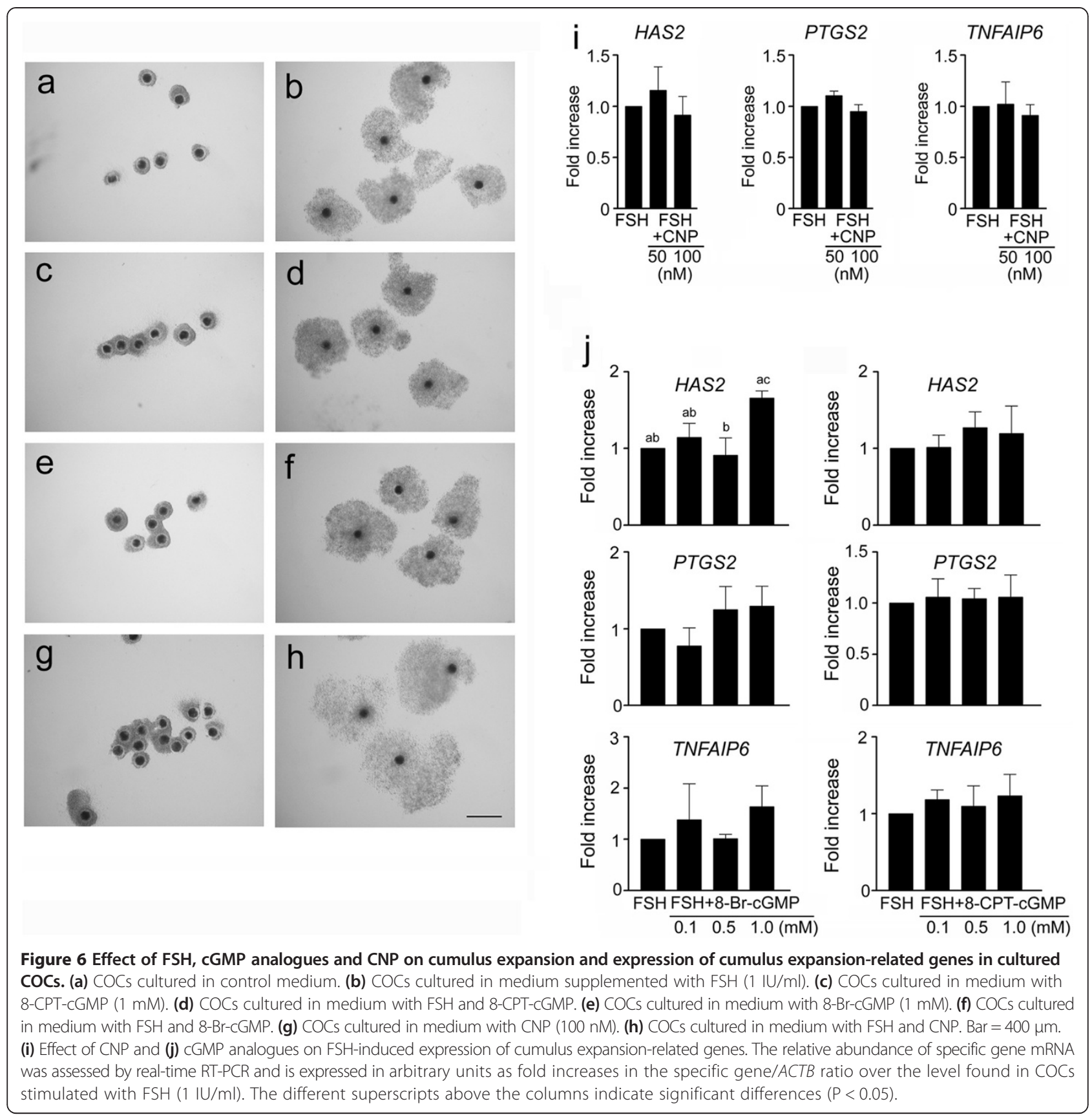

and PDE6C, upregulated in response to gonadotropin, may also hydrolyze the cGMP analogues [17].

In cultured rat follicles, the NO donor SNAP was reported to prevent $\mathrm{LH}$-induced activation of MAPK3/1 and downstream MAPK3/1-dependent events, such as disruption of the gap junctions, oocyte maturation and cumulus expansion [26]. Since the NO downstream effector is the guanylyl cyclase, the authors concluded that the actions of SNAP in the rat follicle are mediated by cGMP. In support of this conclusion, an inhibitor of soluble guanylyl cyclase induced oocyte maturation as well as cumulus expansion. The results of our study demonstrate that neither endogenous cGMP nor exogenous cGMP analogues interfere with the FSH-induced activation of MAPK3/1, expression of cumulus expansionrelated genes and degree of expansion in porcine COCs cultured in vitro. However, we are not able to exclude the possibility that MAPK3/1 activation may be inhibited by NO itself or its donors like SNAP by a cGMPindependent mechanism. NO can block the activity of constitutively active RAS and RAF1 proteins [46] as well as the activity of EGFR [47]. The S-nitrosylation of C-terminal 


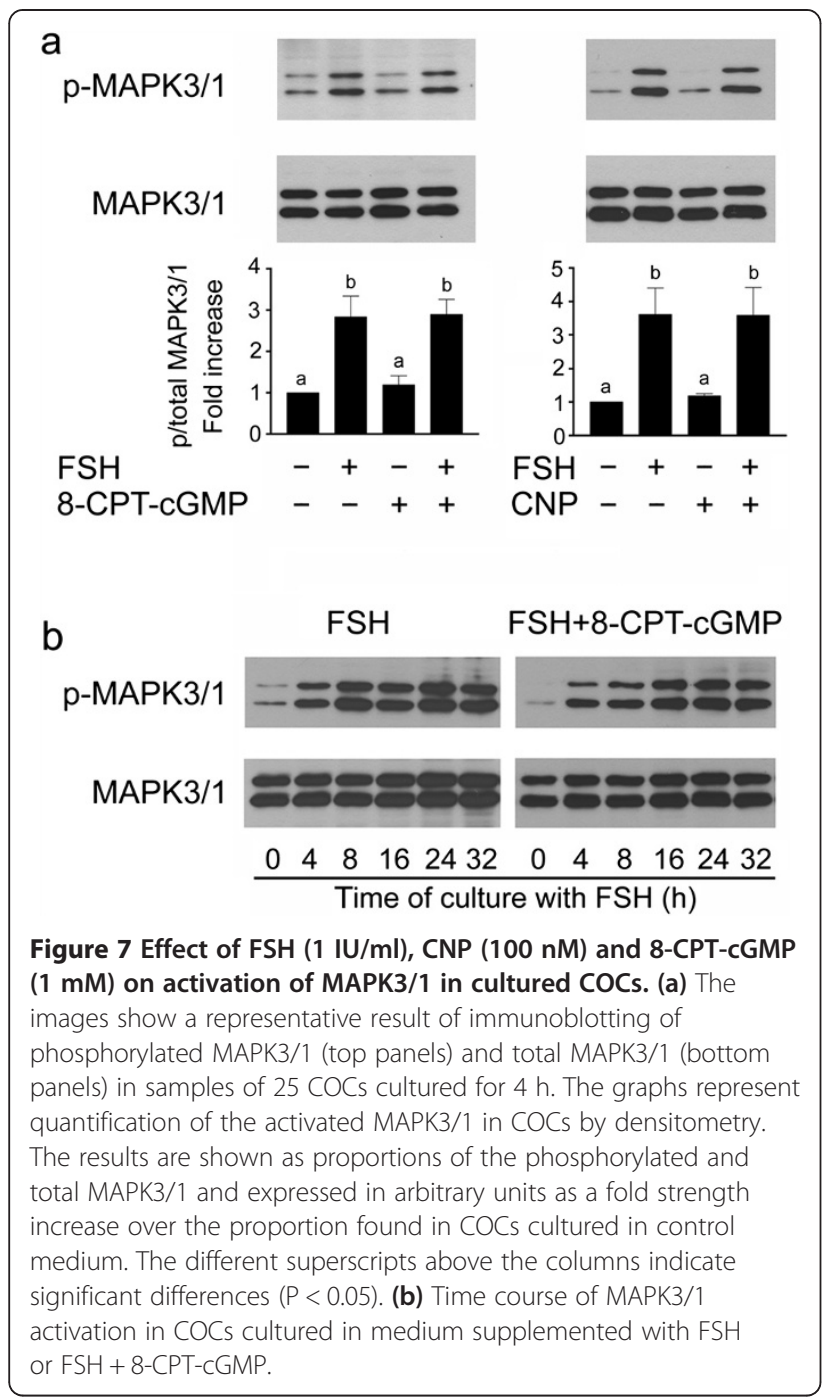

cysteine residues may even increase the activity of RAS [48], probably due to an artificially high concentration of NO [45]. These observations may explain the dual effect of SNAP and other NO-donors on the meiotic maturation reported by some studies $[49,50]$. NO-synthases were also detected in murine [51] and porcine [52,53] oocytes but their role in meiotic maturation is still unclear.

Zhang et al. [27] reported that ANP and 8-Br-cGMP negatively regulates the $\mathrm{FSH}$-induced cumulus expansion of porcine $\mathrm{COC}$ at $44 \mathrm{~h}$ of culture, due to the inhibition of MAPK3/1 signaling. We have shown in our study that 8-CPT-cGMP neither affected the onset of MAPK3/1 activation in the pig COCs at $4 \mathrm{~h}$ of culture nor the course of the kinase activation until $32 \mathrm{~h}$ of culture when the extent of cumulus expansion reached its maximum. A possible effect of 8-Br-cGMP on MAPK3/1 activation was not investigated. However, no significant effect of 8-Br-cGMP on the expression levels of cumulus expansion-related genes indicates that neither 8-CPT-cGMP nor 8-Br-cGMP can inhibit MAPK3/1 activation and cumulus expansion.

\section{Conclusions}

In summary, the data of this study demonstrate that in vitro cultured pig COCs express key components of cGMP synthesis, NPPC and the NPR2, and produce a large amount of cGMP upon stimulation with CNP, which leads to a significant delay in FSH-induced oocyte meiotic resumption. The COCs also respond to exogenous cGMP analogues by inhibiting meiotic resumption, which can be reversed by stimulating the COCs with FSH. However, a high concentration of intracellular cGMP is not able to prevent FSH-induced activation of MAPK3/1 in cumulus cells, the expression of expansionrelated genes and cumulus expansion. Thus, we conclude that the inhibitory effect of cGMP on meiotic resumption of pig cumulus-enclosed oocytes is not caused by the inhibition of MAPK3/1 activation in cumulus cell compartment. The inhibitory mechanism rather consists in the transport of cGMP to the oocyte and the maintenance of a high intracellular concentration of cAMP via the inactivation of PDE3A.

\section{Abbreviations}

8-Br-cGMP: 8-bromo-cGMP; 8-CPT-cGMP: 8-chlorophenylthio-cGMP; ALP: Alkaline phosphatase; ANP: Atrial natriuretic peptide; AREG: Amphiregulin; CAMP: Cyclic adenosine monophosphate; CGMP: Cyclic guanosinmonophosphate; CNP: C-type natriuretic peptide; COC: Cumulus-oocyte complex; EGFR: Epidermal growth factor receptor; EREG: Epiregulin; FSH: Follicle stimulating hormone; GV: Germinal vesicle; GVBD: Germinal vesicle breakdown; HAS2: Hyaluronan synthase 2; LH: Luteinizing hormone; MII: Metaphase II; MAPK3/1: Mitogen-activated protein kinase 3/1; NO: Nitric oxide; NPPC: C-type natriuretic peptide precursor; NPR2: Natriuretic peptide receptor 2; PDE3A: Phospodiesterase 3A; PTGS2: Prostaglandin-endoperoxide synthase 2; SNAP: S-nitroso-Nacetyl-penicillamine; TNFAIP6: Tumor necrosis factor alpha-induced protein 6 .

\section{Competing interests}

The authors declare that they have no competing interests.

\section{Authors' contributions}

$\mathrm{MB}$ designed the experiments, isolated and cultured the COCs, conducted RT-PCR and ELISA, and wrote the manuscript. LN performed RT-PCR, analyzed the data and revised the manuscript. RP conceived the study, performed immunoblotting and wrote the manuscript. All authors read and approved the final manuscript.

\section{Acknowledgments}

This work was supported by the Grant Agency of the Czech Republic (grant P502/11/0593), and by the National Agency for Agricultural Research (grant QI 101A166). Additional support was provided by Institutional Research Concept RVO 67985904 (IAPG, AS CR, v.v.i.). The authors thank Mr. B. J. Watson-Jones from Translation Centre for language corrections.

Received: 30 September 2014 Accepted: 24 December 2014 Published: 7 January 2015

\section{References}

1. Mehlmann LM, Saeki Y, Tanaka S, Brennan TJ, Evsikov AV, Pendola FL, et al. The Gs-linked receptor GPR3 maintains meiotic arrest in mammalian oocytes. Science. 2004;306:1947-50. 
2. $\quad$ Yang $C R$, Wei $Y$, Qi ST, Chen $L$, Zhang $Q H$, Ma JY, et al. The $G$ protein coupled receptor 3 is involved in CAMP and CGMP signaling and maintenance of meiotic arrest in porcine oocytes. PLOS One. 2012;7:e38807.

3. Tsafriri A, Chun SY, Zhang R, Hsueh AJ, Conti M. Oocyte maturation involves compartmentalization and opposing changes of cAMP levels in follicular somatic and germ cells: studies using selective phosphodiesterase inhibitors. Dev Biol. 1996;178:393-402.

4. Wiersma A, Hirsch B, Tsafriri A, Hanssen RG, Van de Kant M, Kloosterboer HJ, et al. Phosphodiesterase 3 inhibitors suppress oocyte maturation and consequent pregnancy without affecting ovulation and cyclicity in rodents. J Clin Invest. 1998;102:532-7.

5. Norris RP, Ratzan WJ, Freudzon M, Mehlmann LM, Krall J, Movsesian MA et al. Cyclic GMP from the surrounding somatic cells regulates cyclic AMP and meiosis in the mouse oocyte. Development. 2009;136:1869-78.

6. Vaccari S, Weeks JL, Hsieh M, Menniti FS, Conti M. Cyclic GMP signaling is involved in the luteinizing hormone-dependent meiotic maturation of mouse oocytes. Biol Reprod. 2009:81:595-604.

7. Zhang M, Su YQ, Sugiura K, Xia G, Eppig JJ. Granulosa cell ligand NPPC and its receptor NPR2 maintain meiotic arrest in mouse oocytes. Science. 2010;330:366-9.

8. Robinson JW, Zhang M, Shuhaibar LC, Norris RP, Geerts A, Wunder F, et al. Luteinizing hormone reduces the activity of the NPR2 guanylyl cyclase in mouse ovarian follicles, contributing to the cyclic GMP decrease that promotes resumption of meiosis in oocytes. Dev Biol. 2012;366:308-16.

9. Norris RP, Freudzon M, Mehlmann LM, Cowan AE, Simon AM, Paul DL, et al. Luteinizing hormone causes MAP kinase-dependent phosphorylation and closure of connexin 43 gap junctions in mouse ovarian follicles: one of two paths to meiotic resumption. Development. 2008;135:3229-38.

10. Norris RP, Freudzon M, Nikolaev VO, Jaffe LA. Epidermal growth factor receptor kinase activity is required for gap junction closure and for part of the decrease in ovarian follicle CGMP in response to LH. Reproduction. 2010;140:655-62.

11. Hsieh M, Thao K, Conti M. Genetic dissection of epidermal growth factor receptor signaling during luteinizing hormone-induced oocyte maturation. PLoS One. 2011;6:e21574

12. Park JY, Su YQ, Ariga M, Law E, Jin SL, Conti M. EGF-like growth factors as mediators of LH action in the ovulatory follicle. Science. 2004;303:682-4

13. Prochazka R, Petlach M, Nagyova E, Nemcova L. Effect of epidermal growth factor-like peptides on pig cumulus cell expansion, oocyte maturation, and acquisition of developmental competence in vitro: comparison with gonadotropins. Reproduction. 2011;141:425-35.

14. Zamah AM, Hsieh M, Chen J, Vigne JL, Rosen MP, Cedars MI, et al. Human oocyte maturation is dependent on LH-stimulated accumulation of the epidermal growth factor-like growth factor, amphiregulin. Hum Reprod. 2010;25:2569-78.

15. Kawamura K, Cheng Y, Kawamura N, Takae S, Okada A, Kawagoe Y, et al. Pre-ovulatory LH/hCG surge decreases C-type natriuretic peptide secretion by ovarian granulosa cells to promote meiotic resumption of pre-ovulatory oocytes. Hum Reprod. 2011;26:3094-101.

16. Zhang M, Su YQ, Sugiura K, Wigglesworth K, Xia G, Eppig JJ. Estradiol promotes and maintains cumulus cell expression of natriuretic peptide receptor 2 (NPR2) and meiotic arrest in mouse oocytes in vitro. Endocrinology. 2011;152:4377-85.

17. Sasseville M, Côté N, Gagnon MC, Richard FJ. Up-regulation of $3^{\prime} 5^{\prime}$-cyclic guanosine monophosphate-specific phosphodiesterase in the porcine cumulus-oocyte complex affects steroidogenesis during in vitro maturation. Endocrinology. 2008;149:5568-76.

18. Lim H, Paria BC, Das SK, Dinchuk JE, Langenbach R, Trzaskos JM, et al, Multiple female reproductive failures in cyclooxygenase 2-deficient mice. Cell. 1997;91:197-208.

19. Fülöp C, Szántó S, Mukhopadhyay D, Bárdos T, Kamath RV, Rugg MS, et al. Impaired cumulus mucification and female sterility in tumor necrosis factor-induced protein-6 deficient mice. Development. 2003;130:2253-61.

20. Richards JS. Ovulation: new factors that prepare the oocyte for fertilization. Mol Cell Endocrinol. 2005;234:75-9.

21. Shimada M, Hernandez-Gonzalez I, Gonzalez-Robayna I, Richards JS. Paracrine and autocrine regulation of epidermal growth factor-like factors in cumulus oocyte complexes and granulosa cells: key roles for prostaglandin synthase 2 and progesterone receptor. Mol Endocrinol. 2006;20:1352-65.

22. Fan HY, Liu Z, Shimada M, Sterneck E, Johnson PF, Hedrick SM, et al. MAPK3/1 (ERK1/2) in ovarian granulosa cells are essential for female fertility. Science. 2009;324:938-41.
23. Yamashita $Y$, Hishinuma M, Shimada M. Activation of PKA, p38 MAPK and ERK1/2 by gonadotropins in cumulus cells is critical for induction of EGF-like factor and TACE/ADAM17 gene expression during in vitro maturation of porcine COCs. J Ovarian Res. 2009;2:20.

24. Prochazka R, Blaha M, Nemcova L. Signaling pathways regulating FSH- and amphiregulin-induced meiotic resumption and cumulus cell expansion in the pig. Reproduction. 2012;144:535-46.

25. Su YQ, Wigglesworth K, Pendola FL, O'Brien MJ, Eppig JJ. Mitogen-activated protein kinase activity in cumulus cells is essential for gonadotropininduced oocyte meiotic resumption and cumulus expansion in the mouse. Endocrinology. 2002;143:2221-32.

26. Sela-Abramovich S, Galiani D, Nevo N, Dekel N. Inhibition of rat oocyte maturation and ovulation by nitric oxide: mechanism of action. Biol Reprod. 2008;78:1111-8.

27. Zhang $M$, Tao $Y$, Zhou B, Xie H, Wang F, Lei $L$, et al. Atrial natriuretic peptide inhibits the actions of FSH and forskolin in meiotic maturation of pig oocytes via different signaling pathways. J Mol Endocrinol. 2005;34:459-72.

28. Santiquet N, Papillon-Dion E, Djender N, Guillemette C, Richard FJ. New elements in the C-type natriuretic peptide signaling pathway inhibiting swine in vitro oocyte meiotic resumption. Biol Reprod. 2014;91:16.

29. Hiradate Y, Hoshino Y, Tanemura K, Sato E. C-type natriuretic peptide inhibits porcine oocyte meiotic resumption. Zygote. 2013;18:1-6. doi:10.1017/ S0967199412000615.

30. Vanderhyden BC, Caron PJ, Buccione R, Eppig JJ. Developmental pattern of the secretion of cumulus expansion-enabling factor by mouse oocytes and the role of oocytes in promoting granulosa cell differentiation. Dev Biol. 1990;140:307-17.

31. Tsuji T, Kiyosu C, Akiyama K, Kunieda T. CNP/NPR2 signaling maintains oocyte meiotic arrest in early antral follicles and is suppressed by EGFRmediated signaling in preovulatory follicles. Mol Reprod Dev. 2012;79:795-802.

32. Motlik J, Fulka J. Breakdown of the germinal vesicle in pig oocytes in vivo and in vitro. J Exp Zool. 1976;198:155-62.

33. Egbert JR, Shuhaibar LC, Edmund AB, Van Helden DA, Robinson JW, Uliasz TF, et al. Dephosphorylation and inactivation of NPR2 guanylyl cyclase in granulosa cells contributes to the LH-induced decrease in CGMP that causes resumption of meiosis in rat oocytes. Development. 2014;141:3594-604.

34. Sela-Abramovich S, Chorev E, Galiani D, Dekel N. Mitogen-activated protein kinase mediates luteinizing hormone-induced breakdown of communication and oocyte maturation in rat ovarian follicles. Endocrinology. 2005;146:1236-44.

35. Sasseville M, Gagnon MC, Guillemette C, Sullivan R, Gilchrist RB, Richard FJ. Regulation of gap junctions in porcine cumulus-oocyte complexes: contributions of granulosa cell contact, gonadotropins, and lipid rafts. Mol Endocrinol. 2009;23:700-10.

36. Santiquet NW, Develle Y, Laroche A, Robert C, Richard FJ. Regulation of gapjunctional communication between cumulus cells during in vitro maturation in swine, a gap-FRAP study. Biol Reprod. 2012;87:46.

37. Wigglesworth K, Lee KB, O’Brien MJ, Peng J, Matzuk MM, Eppig JJ. Bidirectional communication between oocytes and ovarian follicular somatic cells is required for meiotic arrest of mammalian oocytes. Proc Natl Acad Sci U S A. 2013;110:E3723-9.

38. Abbey-Hosch SE, Smirnov D, Potter LR. Differential regulation of NPR-B/GC-B by protein kinase $\mathrm{c}$ and calcium. Biochem Pharmacol. 2005;70:686-94.

39. Zhang M, Tao Y, Xia G, Xie H, Hong H, Wang F, et al. Atrial natriuretic peptide negatively regulates follicle-stimulating hormone-induced porcine oocyte maturation and cumulus expansion via cGMP-dependent protein kinase pathway. Theriogenology. 2005;64:902-16.

40. Downs SM. Hypoxanthine regulation of oocyte maturation in the mouse: insights using hypoxanthine phosphoribosyltransferase-deficient animals. Biol Reprod. 1997;57:54-62.

41. Downs SM, Chen J. EGF-like peptides mediate FSH-induced maturation of cumulus cell-enclosed mouse oocytes. Mol Reprod Dev. 2008;75:105-14.

42. Albuz FK, Sasseville M, Lane M, Armstrong DT, Thompson JG, Gilchrist RB. Simulated physiological oocyte maturation (SPOM): a novel in vitro maturation system that substantially improves embryo yield and pregnancy outcomes. Hum Reprod. 2010;25:2999-3011.

43. Lu Z, Xia G, Zhang J. Protein kinase $C$, rather than protein kinase $A$ is involved in follicle-stimulating hormone-mediated meiotic resumption of mouse cumulus cell-enclosed oocytes in hypoxanthine-supplemented medium. Mol Cell Endocrinol. 2001;182:225-32.

44. Fan HY, Huo LJ, Chen DY, Schatten H, Sun QY. Protein kinase $C$ and mitogen-activated protein kinase cascade in mouse cumulus cells: cross talk and effect on meiotic resumption of oocyte. Biol Reprod. 2004;70:1178-87. 
45. Hanna CB, Yao S, Wu X, Jensen JT. Identification of phosphodiesterase $9 \mathrm{~A}$ as a cyclic guanosine monophosphate-specific phosphodiesterase in germinal vesicle oocytes: a proposed role in the resumption of meiosis. Fertil Steril. 2012;98:487-495.e1.

46. Raines KW, Cao GL, Porsuphatana S, Tsai P, Rosen GM, Shapiro P. Nitric oxide inhibition of ERK1/2 activity in cells expressing neuronal nitric-oxide synthase. J Biol Chem. 2004;279:3933-40.

47. Murillo-Carretero M, Torroglosa A, Castro C, Villalobo A, Estrada C. S-Nitrosylation of the epidermal growth factor receptor: a regulatory mechanism of receptor tyrosine kinase activity. Free Radic Biol Med. 2009;46:471-9.

48. Ibiza S, Pérez-Rodríguez A, Ortega A, Martínez-Ruiz A, Barreiro O, García-Domínguez CA, et al. Endothelial nitric oxide synthase regulates $\mathrm{N}$-Ras activation on the Golgi complex of antigen-stimulated T cells. Proc Natl Acad Sci U S A. 2008;105:10507-12.

49. Bu S, Xia G, Tao Y, Lei L, Zhou B. Dual effects of nitric oxide on meiotic maturation of mouse cumulus cell-enclosed oocytes in vitro. Mol Cell Endocrinol. 2003;207:21-30.

50. Bilodeau-Goeseels S. Effects of manipulating the nitric oxide/cyclic GMP pathway on bovine oocyte meiotic resumption in vitro. Theriogenology. 2007;68:693-701.

51. Huo LJ, Liang CG, Yu LZ, Zhong ZS, Yang ZM, Fan HY, et al. Inducible nitric oxide synthase-derived nitric oxide regulates germinal vesicle breakdown and first polar body emission in the mouse oocyte. Reproduction. 2005:129:403-9.

52. Kim H, Moon C, Ahn M, Lee Y, Kim S, Ha T, et al. Expression of nitric oxide synthase isoforms in the porcine ovary during follicular development. J Vet Sci. 2005;6:97-101.

53. Petr J, Rajmon R, Chmelíková E, Tománek M, Lánská V, Pribánová M, et al. Nitric-oxide-dependent activation of pig oocytes: the role of the cGMPsignaling pathway. Zygote. 2006;14:9-16.

doi:10.1186/1477-7827-13-1

Cite this article as: Blaha et al:: Cyclic guanosine monophosphate does not inhibit gonadotropin-induced activation of mitogen-activated protein kinase $3 / 1$ in pig cumulus-oocyte complexes. Reproductive Biology and Endocrinology 2015 13:1.

\section{Submit your next manuscript to BioMed Central and take full advantage of:}

- Convenient online submission

- Thorough peer review

- No space constraints or color figure charges

- Immediate publication on acceptance

- Inclusion in PubMed, CAS, Scopus and Google Scholar

- Research which is freely available for redistribution 